\title{
Correction to: Survey of Drought-Associated TAWRKY2-D1 Gene Diversity in Bread Wheat and Wheat Relatives
}

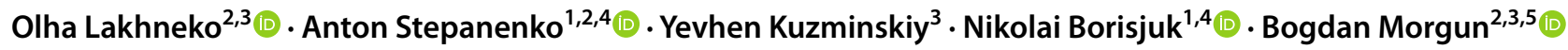

Accepted: 29 June 2021 / Published online: 6 July 2021

๑) Springer Science+Business Media, LLC, part of Springer Nature 2021

Correction to: Molecular Biotechnology

https://doi.org/10.1007/s12033-021-00350-7

In the original version of article unfortunately contains a mistake. The affiliation information of co-authors was incorrect.

The correct author's affiliations information should read as given in this Correction.

These errors do not affect any results or conclusions. The original article has been corrected.

Publisher's Note Springer Nature remains neutral with regard to jurisdictional claims in published maps and institutional affiliations.

The original article can be found online at https://doi.org/10.1007/ s12033-021-00350-7.

Anton Stepanenko

molgen@icbge.org.ua

1 Jiangsu Key Laboratory for Eco-Agricultural Biotechnology Around Hongze Lake, School of Life Sciences, Huaiyin Normal University, Huai' an, China

2 Institute of Cell Biology and Genetic Engineering, National Academy of Sciences of Ukraine, Kyiv, Ukraine

3 National Technical University of Ukraine "Igor Sikorsky Kyiv Polytechnic Institute”, Kyiv, Ukraine

4 Jiangsu Collaborative Innovation Centre of Regional Modern Agriculture \& Environmental Protection, Huaiyin Normal University, Huai' an, China

5 Institute of Plant Physiology and Genetics, National Academy of Sciences of Ukraine, Kyiv, Ukraine 